\title{
A Assistência Psicológica a Crianças em Unidades Básicas de Saúde
}

\section{Psychological assistance to children in the Basic Health Units}

\author{
La asistencia psicológica a niños en Unidades Básicas de Salud
}

\section{Carolina Martins Pereira Alves*}

Universidade Federal do Triângulo Mineiro - UFTM, Uberaba, Minas Gerais, Brasil

\section{Conceição Aparecida Serralha**}

Universidade Federal do Triângulo Mineiro - UFTM, Uberaba, Minas Gerais, Brasil

\begin{abstract}
RESUMO
A presente pesquisa objetivou conhecer a realidade do acompanhamento psicológico a crianças em UBS do município de Uberaba-MG. Participaram do estudo 15 psicólogos, que atuam nessa rede. Para a coleta de dados, foram utilizadas entrevistas semiestruturadas. Os dados receberam tratamento qualitativo mediante Análise de Conteúdo temática, complementada por uma análise da enunciação. Os resultados mostraram que o atendimento às demandas de saúde mental de crianças é realizado por apenas sete psicólogos, dentre os 15 entrevistados, e quando ocorre, é de forma majoritariamente individual. Foi possível levantar as dificuldades na realização deste acompanhamento relacionadas principalmente à falta de recursos, à fragilidade de apoio da gestão e à formação do profissional, além de levantar as possibilidades de atuação em meio a essas dificuldades. Constatou-se que, para a produção de ações coletivas e integradas, o psicólogo deve ter uma atuação generalista, destacando-se a importância de se repensar a formação profissional em Psicologia.
\end{abstract}

Palavras-chave: criança, atenção primária à saúde, psicologia.

\section{ABSTRACT}

This research aimed to know the reality of psychological assistance provided for children in Basic Health Units in Uberaba, state of Minas Gerais. The participants were 15 psychologists working on primary care. Semi-structured interviews were used to collect data. These qualitative data received treatment through Analysis of Content, complemented by analysis of enunciation. The results showed that the demands of children's mental health were attended by only seven among the 15 interviewed psychologists, and, when it happens, they manage it mostly individually. Also, it was possible to notice the difficulties in carrying out this assistance that were mostly related to the lack of resources, the fragility of management support and to professional training, as well as means to develop alternative ways to work under hard conditions. In conclusion, to create better collective and integrated actions, the psychologists must have 
a generalist performance, emphasizing the importance of to rethink the professional education in Psychology.

Keywords: child, primary health care, psychology.

\section{RESUMEN}

Esta investigación tuvo como objetivo conocer la realidad del acompañamiento psicológico a niños en UBS (Unidad Básica de Salud) del municipio de Uberaba-MG. Los participantes del estudio fueron 15 psicólogos que trabajan en esta red. Para la recolección de datos, se utilizaron entrevistas semiestructuradas. Los datos recibieron un tratamiento cualitativo mediante Análisis de Contenido Temático, complementado con un análisis de la enunciación. Los resultados mostraron que la atención de las demandas de salud mental de niños se realiza por sólo siete psicólogos, de entre los 15 entrevistados, y cuando sucede, es de forma mayoritariamente individual. Fue posible identificar las dificultades para llevar a cabo este seguimiento, relacionadas principalmente con la falta de recursos, la debilidad del apoyo a la gestión y la formación profesional, así como también se identificaron las posibilidades de acción en medio de estas dificultades. Se constató que, para la producción de acciones colectivas e integradas, el psicólogo debe tener un accionar generalista, destacándose la importancia de repensar la formación profesional en psicología.

Palabras-clave: niño, atención primaria de salud, psicología.

\section{I ntrodução}

O Ministério da Saúde é responsável pela garantia da saúde como direito de cidadania e aprovou, em 2006, a Política Nacional de Atenção Básica, com o objetivo de desenvolver uma atenção integral à saúde e à autonomia das pessoas. A política visou facilitar o acesso dos usuários à Rede de Saúde e possibilitar maior adequação da gerência de saúde ao contexto de cada população atendida (Ministério da Saúde, 2006; Souza \& Carvalho, 2003).

As práticas na Atenção Básica devem ser democráticas e participativas, na forma de trabalho em equipe, envolvendo ações de saúde individuais e coletivas. O trabalho visa a promoção e proteção da saúde, prevenção de danos ou doenças, diagnósticos, tratamentos, reabilitação e manutenção da saúde, transformando o foco queixa/sintoma em produção de escuta, vínculo e de um fazer coletivo entre profissionais e usuários (Ministério da Saúde, 2006; Sundfeld, 2010).

O espaço em que as ações em Atenção Básica são realizadas é a Unidade Básica de Saúde (UBS), inscrita no cadastro nacional de estabelecimentos de saúde do referido Ministério. A UBS deve se constituir como o contato preferencial dos usuários e a principal porta de entrada à Rede de Saúde, orientada pelos princípios do Sistema Único de Saúde (SUS), como a universalidade e a equidade. O profissional atuante na Atenção Básica deve considerar o sujeito em sua singularidade e complexidade, compreendendo o contexto 
sociocultural no qual está inserido (Souza \& Carvalho, 2003; Ministério da Saúde, 2006).

Este modelo de atuação possibilitou a inserção de diversos profissionais na rede de Atenção à Saúde, a exemplo, o psicólogo. Segundo Böing e Crepaldi (2010), o cuidado em saúde mental deve ser contemplado no campo das práticas na Atenção Básica, uma vez que estas devem seguir princípios como a integralidade e a interdisciplinaridade. A articulação entre saúde mental e atenção básica possibilita a ampliação do acesso da população aos serviços de saúde, prestados de forma mais eficiente e eficaz. Em virtude disso, o psicólogo trabalha com diversas atuações específicas e com os outros profissionais em um trabalho comum e em conjunto. Este processo possibilita intervenções compartilhadas e intersetoriais (Conselho Federal de Psicologia, 2009; Cardoso, 2002).

Diante disso, é necessário que o profissional se atente às demandas dos usuários do serviço. Por demandas, entendem-se os aspectos e necessidades dos pacientes e suas famílias que ultrapassam as queixas iniciais. Para identificá-las, é preciso escutar atentamente, não apenas com o fim de obter informações, como também oferecer um espaço de reflexão e empoderamento do usuário em seu próprio atendimento (Silva, Serralha, \& Laranjo, 2013).

Contudo, existem dificuldades que envolvem as ações do psicólogo na Atenção Básica. Entre estas, citam-se a hegemonia ainda existente do modelo biomédico e a medicalização e psicologização da vida dos usuários, que devem ser evitadas, insistindo no fazer compartilhado a partir da articulação com outros profissionais da equipe. Outras dificuldades que surgem são a desvalorização do profissional atuante na Atenção Básica, a ênfase do trabalho em uma abordagem tradicional e privatista e o baixo investimento financeiro neste nível primário (Conselho Federal de Psicologia, 2009; Jimenez, 2011).

Ressalta-se, assim, a importância de estudos que busquem compreender o contexto de tais dificuldades e desafios, além de discutir possíveis soluções, ao entender que o papel do psicólogo na Atenção Básica não se limita ao apoio às equipes nos cuidados de pacientes com sofrimento mental. Deve abranger a atenção a grupos vulneráveis que necessitem do acompanhamento, a exemplo da infância, fase da vida compreendida até os doze anos de idade incompletos, conforme o Estatuto da Criança e do Adolescente (Brasil, 1990).

De acordo com Cavalcante, Jorge e Santos (2012), a infância não parece ter tanta visibilidade para os profissionais de saúde quanto outras faixas etárias e, ainda que o cuidado esteja voltado para a família, o trabalho é, sobretudo, direcionado aos adultos do núcleo familiar. Para estes autores, a construção de uma rede de atendimento articulada voltada a este público constitui um desafio do trabalho na Atenção Básica. A partir desses dados, ressalta-se a 
importância de se identificar as práticas vigentes nos atendimentos em Unidades Básicas, a fim de revisá-las para melhor e incorporar práticas inovadoras.

O presente estudo, portanto, teve como objetivo conhecer a realidade da assistência psicológica a crianças em Unidades Básicas de Saúde da cidade de Uberaba - Minas Gerais (MG), segundo a percepção dos próprios psicólogos lotados no sistema de Atenção Básica da cidade. Buscou-se investigar a ocorrência de reconhecimento e atendimento de demandas para acompanhamento psicológico de crianças nas UBS, verificar como são realizados os atendimentos psicológicos a este público e identificar as dificuldades e possibilidades de atuação do psicólogo, na Atenção Básica, no tocante ao atendimento de crianças.

\section{Método}

\subsection{Delineamento do Estudo}

Este estudo, de abordagem qualitativa, pode ser caracterizado como exploratório, transversal e empírico, uma vez que os dados coletados foram relativos às ideias e opiniões dos participantes apenas no momento de realização da pesquisa e partem de vivências dos participantes e dos pesquisadores (Richardson, 2011).

\subsection{Participantes}

A amostra foi constituída por profissionais graduados em Psicologia, com atuação na assistência à saúde da população, cadastrados na rede de Atenção Básica do município de Uberaba-MG. Esses profissionais poderiam ser de qualquer gênero e deveriam ter idade igual ou maior que 18 anos, estar atuando em UBS e aceitar participar da pesquisa.

O fechamento da amostra se deu por exaustão, constituindo como participantes todos os indivíduos disponíveis que faziam parte do universo definido no estudo (Fontanella, Ricas, \& Turato, 2008). A disponibilidade referiu-se ao acesso a estes profissionais durante 0 período de coleta de dados, de junho a outubro de 2015, e ao aceite em participar da pesquisa.

\subsection{Instrumentos}

O instrumento utilizado neste estudo foi a entrevista semiestruturada. As entrevistas duraram em média 30 minutos e foram audiogravadas e transcritas na íntegra. O uso de entrevistas é defendido por Fraser e Gondim (2004), por caracterizarem uma 
forma de interação que valoriza o uso da palavra ao dar sentido à realidade, possibilitando maior compreensão de significados, valores e opiniões acerca do tema estudado.

\subsection{Procedimentos de coleta de dados}

As 24 UBS que atendem à zona urbana do município de Uberaba-MG foram contatadas, para o levantamento dos psicólogos que atuam nestes espaços. Destas, apenas 16 relataram ter o trabalho do profissional psicólogo. De posse desse levantamento, o contato com os profissionais se deu de forma direta, pelo telefone registrado de cada UBS. A partir deste telefonema, foi agendado, com os psicólogos que aceitaram participar da pesquisa, um encontro único individualizado, no qual foi realizada uma entrevista semiestruturada, com questões relacionadas ao tema em estudo.

\subsection{Procedimentos de análise de dados}

Os dados receberam tratamento qualitativo mediante Análise de Conteúdo das informações obtidas na entrevista, com a finalidade de oferecer um significado, tendo em conta palavras pré-escolhidas pelo locutor, frequência de recorrência de certos termos, aparato e andamento do discurso. Utilizou-se a análise temática complementada por uma análise da enunciação, a fim de compreender a comunicação de temas específicos a partir da produção da linguagem e de elementos formais atípicos, tais como silêncios, omissões e uso da retórica (Bardin, 1977/2011).

\subsection{Procedimentos éticos}

Para a realização da pesquisa, inicialmente se obteve a autorização da Secretaria Municipal de Saúde da referida cidade e a aprovação do projeto pelo Comitê de Ética em Pesquisa (CEP) da UFTM, sob o parecer de número 1.063.855. Além disso, antes do início das entrevistas, os psicólogos convidados a participar do estudo foram esclarecidos sobre seus objetivos e condições, tendo assinado o Termo de Consentimento Livre e Esclarecido.

\section{Resultados}

Participaram da pesquisa 15 psicólogos que atuam em Unidades Básicas de Saúde da cidade de Uberaba-MG. Ao todo, foram 14 mulheres e um homem, na faixa etária entre 27 e 59 anos, estando a maioria acima dos 40 anos, conforme Tabela 1. 


$\begin{array}{cccc}\text { Tabela } 1 \text { - Descrição de dados dos participantes da pesquisa } \\ \text { Participante } & \text { Gênero } & \text { Idade } & \text { Tempo de atuação na área } \\ \text { P1 } & \text { Masculino } & 43 \text { anos } & 2 \text { anos } \\ \text { P2 } & \text { Feminino } & 53 \text { anos } & 20 \text { anos } \\ \text { P3 } & \text { Feminino } & 49 \text { anos } & 21 \text { anos } \\ \text { P4 } & \text { Feminino } & 50 \text { anos } & 5 \text { anos e meio } \\ \text { P5 } & \text { Feminino } & 48 \text { anos } & 4 \text { anos } \\ \text { P6 } & \text { Feminino } & 52 \text { anos } & 21 \text { anos } \\ \text { P7 } & \text { Feminino } & 48 \text { anos } & 21 \text { anos } \\ \text { P8 } & \text { Feminino } & 37 \text { anos } & 4 \text { anos } \\ \text { P9 } & \text { Feminino } & 35 \text { anos } & 4 \text { anos e meio } \\ \text { P10 } & \text { Feminino } & 36 \text { anos } & 2 \text { anos } \\ \text { P11 } & \text { Feminino } & 27 \text { anos } & 3 \text { meses } \\ \text { P12 } & \text { Feminino } & 55 \text { anos } & 27 \text { anos } \\ \text { P13 } & \text { Feminino } & 50 \text { anos } & 21 \text { anos } \\ \text { P14 } & \text { Feminino } & 59 \text { anos } & 21 \text { anos } \\ \text { P15 } & \text { Feminino } & 31 \text { anos } & 3 \text { anos e meio }\end{array}$

A partir da análise dos dados, foi possível chegar a três categorias temáticas. A primeira categoria, denominada Os Atendimentos Psicológicos na Atenção Básica, foi dividida em duas subcategorias: 1) O Reconhecimento e Atendimento da Demanda e 2) Modalidades de Atendimento Psicológico. A segunda categoria definida foi denominada As Demandas para Acompanhamento Psicológico de Crianças e a terceira categoria, A Atenção Psicológica à Crianças na Atenção Básica, foi dividida em 1) Dificuldades na Atuação e 2) Possibilidades de Atuação.

\subsection{Os Atendimentos Psicológicos na Atenção Básica}

\subsubsection{O Reconhecimento e Atendimento da Demanda}

Todos os psicólogos entrevistados reconheceram a existência de uma grande demanda para o acompanhamento psicológico do público infantil. Entretanto, apenas sete (P1, P6, P8, P10, P11, P12 e P13), dentre os 15 entrevistados, realizam este acompanhamento com crianças nas UBS em que trabalham.

Relacionando os fatores idade e tempo de atuação na Atenção Básica, vê-se que todos os seis psicólogos com idade inferior a 45 anos (P1, P8, P9, P10, P11 e P15) atuam em UBS há menos de seis anos e que a maioria deles (P1, P8, P10 e P11) realiza atendimentos com 
crianças. Dos profissionais com idade superior a essa, dois (P4 e P5) trabalham na rede de Atenção Básica há menos de seis anos e não os realizam. Os sete restantes (P2, P3, P6, P7, P12, P13 e P14) atuam na Atenção Básica há mais de 20 anos e apenas três (P6, P12 e P13) realizam o acompanhamento supracitado.

Entende-se, desta forma, que o acompanhamento psicológico de crianças é realizado principalmente pelos psicólogos mais novos e que atuam há menos tempo na Atenção Básica. Dentre os psicólogos com mais tempo de atuação, poucos realizam atendimentos ao público infantil. P6 e P14 relacionam este movimento à possibilidade de que a menor disposição física do profissional, em razão da idade, indisponha-o ao atendimento de crianças. No geral, os participantes citaram como justificativas para a não realização de atendimentos psicológicos com crianças: a presença de outro psicólogo na UBS que já o realizava; limitações da disposição física; e falta de envolvimento dos pais, de apoio da gestão e de identificação pessoal com esse público.

A saída encontrada para os profissionais que não realizam atendimentos a este público é o encaminhamento para outros serviços de saúde. Contudo, muitos ressaltam a dificuldade de realizar esses encaminhamentos em razão do pequeno número de profissionais para os quais é possível encaminhar e da existência de filas de espera, nas quais o paciente encaminhado pode demorar quase um ano para ser chamado. De acordo com P15, "encaminhar era a mesma coisa de deixar essa criança sem atendimento". Na continuidade do relato desta participante, puderam ser percebidos sentimentos de culpa e alívio se alternando:

É difícil falar "eu não atendo". Eu não atendo por quê? [...] Não é a minha formação específica... é por isso que eu evito atender, como você pode ver, a sala não tá formatada, então, eu não atendo. Mas eu tento prestar o máximo de orientação que eu puder, no que estiver ao meu alcance [...] E aí, eu também aproveito da situação, porque eu também tenho uma fila de espera enorme... alivia o meu lado [...].

Já para P2 e P13, os atendimentos a crianças na Atenção Básica, mesmo com dificuldades, ocorrem normalmente, conforme relato a seguir: "praticamente todo postinho tem psicólogo que atende" (P2). Contudo, parece ser uma percepção não muita realista, pois o restante dos psicólogos entrevistados percebe esse atendimento pouco frequente, além de notar certa indisponibilidade dos profissionais para realizá-lo. Isso pôde ser notado na resposta de uma participante, ao ser questionada acerca do atendimento psicológico ao público infantil de forma geral: 
Ninguém quer trabalhar com esse público. A verdade é que a criança está órfã de psicólogos na rede pública. [...] A família não quer, a escola não quer, e o serviço de saúde acaba que também não quer as crianças e os adolescentes (P6).

À exceção de $\mathrm{P} 13$, todos os outros psicólogos que realizam $\mathrm{O}$ acompanhamento de crianças e uma, que não o realiza (P9), defendem o trabalho generalista do profissional, ou seja, que este deve atender demandas de toda a população do território da UBS. P2, P7, P13 e P15 questionam este posicionamento, conforme o seguinte excerto:

Nós temos o clínico geral, mas ele atende adulto. Nós temos os pediatras que atendem as crianças. Então é um profissional que fez uma formação, uma residência específica pra isso. [...] E o psicólogo tem que atender tudo! Então eu acho que deveria ter profissionais específicos nas unidades básicas que tivessem uma formação (P15).

Nota-se, neste relato, a indignação de $\mathrm{P} 15$, em relação à possibilidade de atender como especialista, concedida aos profissionais médicos na Atenção Básica, mas não aos psicólogos, já que estes devem atender demandas independentemente de sua formação específica e da faixa etária da população do território.

\subsubsection{Modalidades de Atendimento Psicológico}

Os atendimentos realizados foram identificados como majoritariamente individuais pelos psicólogos entrevistados. Apenas três ( $P 1, P 9$ e $P 12$ ) relataram planos futuros de realizar 0 acompanhamento em grupo de crianças, ainda que P9 não realize atualmente atendimentos a este público. Somente uma psicóloga (P11) relatou realizar grupos com este público em seu cotidiano.

Foram relatadas poucas possibilidades de atuação, justificadas pela escassez de recursos e pelas limitações relacionadas à idade, nos casos de P6 e P14.

Individual, só tem condição de ser individual. [...] Por dois anos fiz um grupo na creche, fiz com criança e com préadolescentes, mas parei mais ou menos pelas mesmas questões, dificuldades materiais, e físicas mesmo, da idade (P6).

Nove participantes (P3, P5, P6, P8, P9, P11, P12, P13 e P14) citaram o contato do psicólogo com o restante da equipe multiprofissional como fator importante no trabalho em Saúde Coletiva. Muitos 
profissionais (P3, P5, P8, P9, P10, P11, P12, P13 e P14) citaram, como fatores positivos neste contato, o número cada vez maior de encaminhamentos recebidos e, especialmente, nos casos de P8, P11, P12 e P13, houve relatos de uma relação saudável entre os profissionais da UBS. Pôde ser constatado, contudo, que raramente o trabalho multiprofissional foi além do contato via encaminhamentos realizados e recebidos. De acordo com P6: "o psicólogo não é incluído ou valorizado na Estratégia de Saúde da Família".

\subsection{As Demandas para Acompanhamento Psicológico de Crianças}

Na percepção dos participantes da pesquisa, os encaminhamentos para atendimento psicológico de crianças são realizados principalmente por professores e diretores de escolas, citados por 12 psicólogos (P1, P2, P3, P4, P5, P6, P9, P10, P11, P12, P13 e P14) e por profissionais da UBS, em especial Agentes Comunitários de Saúde e médicos (P2, P3, P4, P5, P8, P9, P10, P12, P13 e P14), citados por 10 deles. A procura espontânea, em que pais/responsáveis buscam por ajuda e respostas diante de comportamentos desafiadores dos filhos, foi citada por todos os profissionais entrevistados.

Em relação aos encaminhamentos realizados por profissionais da saúde, seis psicólogos (P3, P5, P8, P9, P12 e P14) destacaram que seu contato mais frequente é com médicos, com os quais também estabelece parcerias. Duas profissionais (P6 e P12) relataram que recebem encaminhamentos de profissionais que atendem em UBS de outro território do município, corroborando o fato de serem poucos os psicólogos que atendem crianças.

Segundo os participantes, da escola origina a maior parte dos encaminhamentos recebidos, embora nem sempre o contato com esta se mantenha após o início do atendimento. Entretanto, os profissionais relataram que, na avaliação, não era em todos os casos que se constatava ser a demanda do atendimento psicológico relacionada a um problema exclusivo da criança.

Você acaba que fica com a criança - é ela que a família libera. Mas, muitas vezes, a questão nem tem tanto a ver com ela. Eu peço a participação dos pais [...] e, às vezes, a pessoa até esquece que o motivo da consulta era a criança (P6).

Assim, embora muitos tenham relatado queixas relacionadas à escola - dez participantes (P1, P2, P3, P4, P6, P8, P9, P10, P11 e P13) - e ao comportamento da criança - oito participantes (P1, P5, P6, P10, $\mathrm{P} 11, \mathrm{P} 12, \mathrm{P} 13$ e P15) -, os profissionais compreendem ser importante - reconhecimento da real demanda para o acompanhamento psicológico. Em muitos casos, a criança apresenta um sintoma que 
origina a busca pelo atendimento, mas, na realidade, são a família e a relação parental que necessitam de intervenção.

\subsection{A Atenção Psicológica a Crianças na Atenção Básica}

\subsubsection{Dificuldades na Atuação}

Todos os psicólogos entrevistados relataram dificuldades na atuação com o público infantil. Algumas dessas dificuldades se sobressaíram: a falta de profissionais; a não adesão ao tratamento por parte do paciente e de sua família; a falta de apoio da gestão, inclusive em termos de capacitação; a ausência dos pais e responsáveis no processo; a inadequação do espaço físico e dos recursos materiais; e a insuficiente formação profissional.

Para os participantes, a família cria a expectativa de que o psicólogo poderá resolver o problema apresentado pela criança, isentando-se de responsabilidades e demonstrando não ter consciência de sua própria demanda. Este fator pode gerar abandono do tratamento e, por consequência, um sentimento de frustração tanto no profissional quanto no grupo familiar.

Os pais, parentes, depositam em você [...]toda a expectativa de que você vai solucionar, como se a gente tivesse uma varinha de condão, e tudo bem rápido. E aí o que você percebe é que quando começa a melhorar, tira a criança do acompanhamento (P12).

Em relação a outros aspectos, todos os psicólogos, com exceção de P13, relataram que as maiores dificuldades no atendimento à crianças são as relacionadas à adequação do espaço físico e dos recursos materiais necessários, e ao apoio dos órgãos gestores em saúde no município. Lidar com essas dificuldades são os principais desafios para o atendimento a esse público, bem como realizar ações diferentes do acompanhamento individual.

[...] eu tive uma colega que tomou posse até antes de mim, ela não tá mais [...] e um dia eu perguntei pra ela: 'Fulana, você atende?' Ela falou: 'Deus me livre, de jeito nenhum, como é que eu vou atender criança, lá não tem nada! Mal tem folha pra mim anotar as coisas, eu vou atender criança?'[...] Eu não conseguiria imaginar atender criança sem estrutura. E a gente não tem essa estrutura nas unidades básicas (P15).

A maioria dos psicólogos que realiza o atendimento infantil (P1, P6, $\mathrm{P} 10, \mathrm{P} 11$ e P12) relatou que com o próprio salário arcam com as despesas de material, apesar de compreenderem que esta é uma 
competência da administração pública. Além disso, oito participantes (P1, P3, P4, P6, P11, P12, P14 e P15) relataram a fragilidade do apoio que recebem em termos de capacitação, muitas vezes relacionada às constantes mudanças nas coordenações dos serviços de saúde. Pôde ser notado certo desamparo no relato dos profissionais para se referirem a seus sentimentos em relação à gestão pública em saúde.

Sinto um certo abandono.[...] Não há fiscalização, as dificuldades surgem e as soluções são sempre complicadas, um desamparo, o acesso à referência é muito difícil.[...] 0 profissional fica à própria sorte (P1).

Uma das participantes (P4) relatou existir empenho da coordenação da Unidade e da Secretaria de Saúde, mas que há um entrave nesse sistema. Ela expôs, de forma preocupada: "Nem sei onde conseguiria o apoio". Os outros sete participantes (P2, P5, P7, P8, P9, P10 e P13), entretanto, possuem uma visão mais otimista sobre o apoio que 0 psicólogo recebe:

Tô tendo apoio da colega de trabalho, muito, de material que preciso. Da Secretaria, começa a verificar cursos, que não são específicos, mas tá começando a ter [...] Eu vejo que as secretarias começam a dar um apoio... Cabe ao profissional também buscar, querer (P9).

Pôde ser notado que as dificuldades se encontravam associadas às justificativas para o não atendimento de crianças por parte dos psicólogos que não o realizavam. Contudo, mesmo os psicólogos que atendiam, relataram dificuldades com a falta de recursos materiais, de apoio dos órgãos gestores e de envolvimento dos familiares responsáveis pela criança atendida.

\subsubsection{Possibilidades de Atuação}

Diante das dificuldades expostas, foi solicitado aos participantes que discorressem sobre as possibilidades de atuação em seu contexto de trabalho. Nesse sentido, foi ressaltada a crescente solicitação do trabalho do psicólogo pelo usuário, bem como pelos profissionais da equipe. Isto demonstra um aumento da visibilidade do trabalho do psicólogo, rompendo com antigos preconceitos e aumentando o número de procura espontânea e de encaminhamentos.

Hoje você vê que, de uma forma geral, dentro da unidade, é incluído o trabalho, é solicitado, e isso reflete na comunidade [...] a gente está mais visto na situação de saúde e menos de problema, de loucura (P8). 
A importância das atividades voltadas para a prevenção de doenças e a promoção da saúde da população infantil também foi citada por seis psicólogos (P1, P5, P6, P9, P11 e P12), ainda que aconteça pouco na prática destes profissionais. Todos os que citaram esta possibilidade ressaltaram a necessidade de um investimento maior do psicólogo, de uma forma geral, nessas atividades.

Outra possibilidade, para o enfrentamento das dificuldades apontadas, foi a de contratação de novos profissionais e melhoria da estrutura da rede. Seis participantes (P1, P3, P4, P6, P11 e P14) destacaram, também, a possibilidade de diálogo com outras instituições, em especial a escola, proporcionando um trabalho de rede.

O principal mesmo é que as crianças precisam das instituições, e tem que cobrar. [...] Às vezes, a queixa tá muito ligada ao enquadramento que se espera na escola, não tanto com uma questão da criança mesmo, e é no contexto de lá que isso tá acontecendo e precisa ser visto (P6).

A necessidade de melhoria dos recursos materiais, tanto quantitativa, como qualitativa, foi bastante discutida no decorrer das entrevistas, em prol do fortalecimento do trabalho do psicólogo. Contudo, alguns psicólogos (P1, P5 e P12), mesmo considerando essencial o investimento da Secretaria de Saúde do município nestes recursos, destacaram a vantagem, no atendimento da criança, da capacidade desta de reinventar espaços e materiais.

Nós temos que contar, também, que a criança é muito criativa. Então, mesmo com pouco material, dá pra trabalhar, com revista, desenhos [...] Esse é o recurso que a gente tem pra trabalhar (P12).

A importância do investimento na formação profissional, a fim de que os desafios anteriormente propostos sejam vencidos, também foi citada por alguns psicólogos (P1, P5, P7 e P14). Para estes, é na formação que se encontra a possibilidade de uma atuação cada vez mais capaz e implicada.

Olha, eu penso muito que é a nossa própria formação. [...] temos que investir na capacitação, nessa condição de fazer análise, de pensar em por que não atender, é medo de não ser capaz? É realmente os recursos que não tem? E se não tem, o que a gente pode fazer para que venha a ter? (P7). 
Sete psicólogos (P5, P6, P7, P8, P11, P12 e P13) destacaram o prazer em trabalhar com aquilo que escolheram, tanto em relação à profissão específica quanto na rede de Atenção Básica, apesar das dificuldades colocadas, o que leva à maior satisfação com a profissão e maior empenho nas ações que se propõe a realizar.

\section{Discussão}

O reconhecimento unânime da existência de uma grande demanda para atendimentos psicológicos de crianças na cidade de Uberaba-MG vai ao encontro da estimativa do Ministério da Saúde (2005) de que, de $10 \%$ a $20 \%$ da população infanto-juvenil necessitam de cuidados em Saúde Mental. Por outro lado, pode estar relacionada à escassez de profissionais que se voltam ao cuidado desse público, destacada pelos entrevistados.

Segundo Silva e Vieira (2013), a falta de profissionais pode ser considerada um agravante no acesso dessa população aos serviços de saúde, o que se liga à percepção de uma demanda demasiado grande para o número de profissionais disponíveis para atendê-la. Esta informação contrasta com uma das principais características das unidades da rede de Atenção Básica, que é a de serem portas de entrada aos serviços de saúde. A escuta a queixa do usuário dá legitimidade ao seu sofrimento e já corresponde a uma forma de cuidado (Ministério da Saúde, 2005).

Entretanto, encaminhamentos para outros serviços são necessários, quando a rede de Atenção Básica não consegue resolver as demandas do usuário que a procura. De acordo com o Ministério da Saúde (2005), faz-se necessária a redefinição da forma como este encaminhamento é concebido e realizado. A proposta é de Encaminhamento Implicado, no qual aquele que encaminha se inclui no processo, ou seja, se torna responsável pelo acompanhamento do caso até que este chegue efetivamente ao seu novo destino. Envolve, assim, a aplicabilidade do princípio da Intersetorialidade, em que os vários serviços da rede de saúde dialogam entre si a fim de que o usuário seja atendido de forma integral.

Em UBS, nas quais o psicólogo não realiza nenhuma forma de atendimento às demandas de crianças, percebem-se lacunas na constituição da rede como um serviço de portas abertas. Cavalcante, Jorge e Santos (2012) relatam a insegurança dos profissionais de saúde em atender casos de problemas em saúde mental, especialmente infantil, com o discurso de que esses casos seriam mais bem conduzidos por um profissional mais qualificado. Esse discurso se distancia da atenção coletiva e integral.

Essa indisposição entra em choque com a ideia do profissional generalista, que, de acordo com Böing e Crepaldi (2010), se constitui 
como forma privilegiada de trabalho do psicólogo no contexto da Atenção Básica, possibilitando que a atenção à saúde seja efetiva e integral. Entende-se que o profissional generalista seja capaz de atender demandas da Atenção Primária em Saúde, com foco na família e na comunidade (Ministério da Saúde, 2006).

Entende-se ainda que, ao psicólogo que trabalha na rede de Atenção Básica, não é necessário um título de especialista para acolher as necessidades da população infantil; a formação durante a graduação deve capacitá-lo para isso. Por um lado, a saída para a falta de afinidade relatada, deveria ser ao menos a escuta da demanda da criança, possibilitando um encaminhamento compromissado com o atendimento a ela. Por outro lado, é importante repensar como esses profissionais são admitidos em um serviço, que, na realidade da saúde pública brasileira atual, não pode oferecer a possibilidade de que o profissional escolha a quem atender, uma vez que não há profissionais em número suficiente para isso. A admissão deve se pautar em profissionais que se sintam preparados para atender toda a população do seu território de abrangência (Böing \& Crepaldi, 2010; Ministério da Saúde, 2005).

Além disso, destaca-se a frustração dos psicólogos entrevistados pela impossibilidade de atender todas as demandas que chegam aos serviços de saúde. Isso pode levar o profissional a selecionar casos para atendimento, não por prioridade em relação aos agravos, mas por sentir maior preparo para atender. Esses profissionais, quando não atendem o público infantil, têm dificuldades de realizar encaminhamentos em razão do reduzido número de profissionais e da incerteza de que a criança encaminhada será atendida em outro serviço.

Dessa forma, a atuação do profissional acaba por se tornar limitada, em contraposição às várias possibilidades de atuação do psicólogo na rede de Atenção Básica. Segundo Cardoso (2002) e Jimenez (2011), ele pode atuar por meio de grupos informativos ou psicoterapêuticos, dinâmicas, visitas domiciliares, atendimentos individuais, quando necessários, e discussões com as equipes, buscando a integralidade do atendimento ao usuário e a desmistificação da Psicologia. Entende-se que, para que aconteça uma prática que contemple o indivíduo em sua totalidade, é essencial o trabalho em equipe multiprofissional.

No presente estudo, pôde ser percebido que o trabalho em equipe multiprofissional é um modelo ainda incipiente, em que as discussões em equipe se resumem muitas vezes a encaminhamentos. Cela e Oliveira (2015), considerando a saúde mental como intrínseca ao cuidado integral, dispõem sobre a necessidade de um trabalho em que profissionais e comunidade se corresponsabilizem pelas ações em saúde. É preciso que o profissional não se habitue apenas a uma atuação solitária e isolada de outros profissionais e saberes. 
Para que isso aconteça, é importante que haja articulação e definição das expectativas do psicólogo e da equipe em relação à sua atuação na UBS. Segundo Archanjo e Schraiber (2012), a exigência é a de que o profissional atenda o maior número de pessoas possível, em detrimento de outras ações. Esta exigência foi percebida no relato dos participantes da pesquisa, gerando atendimentos individualizados, com poucas ações coletivas. Ainda assim, alguns psicólogos conseguem se inserir no cotidiano de serviço da Unidade, mostrando que é possível a contextualização da realidade dos indivíduos e do ambiente comunitário, em uma visão integrada de diferentes saberes (Bittencourt \& Mateus, 2006; Cardoso, 2002).

De acordo com Jimenez (2011), o estudo das demandas propicia o desenvolvimento de ações interdisciplinares e intersetoriais. Para a autora, as demandas que envolvem queixas emocionais devem ser compreendidas em seu contexto social. Compreende-se, dessa forma, que o desamparo relatado pelos profissionais em relação à situação da criança na sociedade não ocorre apenas em nível individual, mas também social, em que famílias se sentem abandonadas em suas necessidades e podem não conseguir suprir as de seus filhos.

A citada autora complementa que essas demandas de crianças envolvem fatores orgânicos, sociofamiliares e principalmente questões intraescolares, citadas pelos participantes. Zibetti, Souza e Queiróz (2010) afirmam que o sistema educacional vem transferindo para outros órgãos, como o sistema de saúde, a responsabilidade sobre a aprendizagem de crianças caracterizadas como "problema", contribuindo para a manutenção de práticas excludentes e estigmatizantes dessas crianças tanto em casa quanto na escola.

É possível perceber que essas questões chegam aos psicólogos entrevistados e que grande parte deles se empenha em compreender a demanda e se preocupa com a continuidade do atendimento. Além disso, os profissionais estão atentos àqueles que deverão receber o foco da intervenção. Silva, Serralha e Laranjo (2013) e Mantovani, Marturano e Silvares (2010) ressaltam a importância da escuta atenta dos filhos pelos pais e da inserção destes no processo de cuidado. É necessário diferenciar os casos que se beneficiariam com uma abordagem focada na criança daqueles que necessitam de ajudas em outros aspectos, envolvendo demandas mais pertinentes à família que à criança propriamente dita.

Os relatos de abandono do tratamento, principalmente nos casos em que foi necessário o acompanhamento psicológico da família ou de algum familiar, alertam para a necessidade de que pacientes e seus responsáveis estejam sensibilizados para os motivos do encaminhamento e para a importância do acompanhamento psicológico. Em diálogo com Mantovani, Marturano e Silvares (2010), a acessibilidade ao atendimento psicológico não garante sua 
permanência, tendo em vista que famílias com maior vulnerabilidade social possuem altos índices de abandono do tratamento.

De acordo com Finkel (2009), a partir do crescente número de teorias que vieram se desenvolvendo, hoje a criança é vista dentro de uma dinâmica familiar e seu problema é considerado, no diagnóstico e tratamento, como pertencente a esta. Contudo, embora a maior procura pelos atendimentos seja dos próprios pais, estes tendem a se afastar quando passam a compreender que o problema vai além do sintoma apresentado pela criança, defrontando com suas próprias dificuldades.

A inadequação do espaço físico e dos recursos materiais foi apontada como outra dificuldade no trabalho com a criança na Atenção Básica. Pode-se compreender a apreensão dos profissionais participantes com a falta de materiais para o atendimento de crianças, uma vez que, independentemente da abordagem, a utilização de recursos lúdicos facilita muito o contato e a expressão da criança. A atividade lúdica é importante para o desenvolvimento emocional e para a inserção na cultura e é a partir do brincar que a criança pode organizar e conviver com sua realidade interna. Desta forma, a possibilidade de brincar constitui uma forma de cuidado em saúde mental infantil (Alves \& Emmel, 2008; Conti \& Souza, 2010).

A falta de recursos materiais, nesta pesquisa, foi relacionada ao escasso apoio da gestão, intensificando os sentimentos de frustração e angústia do psicólogo em relação ao serviço na Atenção Básica. Entretanto, para que o profissional seja capaz de se reinventar diante das faltas com as quais se depara, é essencial o investimento na formação. A formação em Psicologia ainda se mostra muitas vezes distante da realidade do trabalho na comunidade. Nessa ótica, tornase importante que os profissionais estejam sempre em busca de crescimento dentro da área em que atuam (Lima, Brito, \& Firmino, 2011).

Lentamente, a Psicologia vem se aproximando do SUS, de diferentes realidades e lugares de atuação. A quebra de preconceitos e consequente valorização do trabalho do psicólogo relacionam-se ao desenvolvimento da formação na área. Assim, a formação que visa à reflexão crítica e ao entendimento da comunidade permite ao psicólogo o trabalho como generalista, sem distinção de público a ser atendido (Dimenstein \& Macedo, 2012).

Assim, aos poucos, a atuação do psicólogo ganha espaço na rede de Atenção Básica. Nota-se que o trabalho do psicólogo com o público infantil é visto como relevante para os participantes da pesquisa e, apesar das dificuldades relatadas, os psicólogos que realizam atendimentos a crianças visualizam possibilidades de enfrentamento e crescimento. Entende-se, assim, que a assistência psicológica a crianças na rede de Atenção Básica do município de Uberaba-MG é possível, mesmo com suas limitações materiais e burocráticas. 
É, sobretudo, fundamental o desenvolvimento de atividades de promoção e prevenção voltadas à saúde mental infantil, pois a procura pelo atendimento psicológico a esse público é crescente e, na perspectiva dos participantes, consideravelmente maior que a oferta, denunciando a necessidade de mais psicólogos voltados ao atendimento de demandas relativas à saúde mental infantil. Vê-se ainda a importância da articulação entre família, ambiente escolar e serviços de saúde numa atuação conjunta. Contudo, para que este trabalho seja dinâmico e frequente, é necessária a disponibilização de recursos internos e materiais.

Há necessidade de que o tema do presente estudo tenha maior visibilidade e seja constantemente debatido no meio acadêmico e no cotidiano dos profissionais da rede de Atenção Básica. Nesse sentido, este estudo contribuiu por ouvir os psicólogos, suas dificuldades e propostas de atuação. Contudo, novas pesquisas são necessárias sobre o acompanhamento de crianças em rede e, a partir disso, possibilitar a construção de saberes e de possíveis soluções para os problemas encontrados.

\section{Referências}

Alves, H. C., \& Emmel, M. L. G. (2008). Abordagem bioecológica e narrativas orais: um estudo com crianças vitimizadas. Paidéia, 18(39), 85-100. Retirado de http://www.scielo.br/pdf/paideia/v18n39/v18n39a09.pdf

Archanjo, M. A., \& Schraiber, L. B. (2012). A atuação dos psicólogos em Unidades Básicas de Saúde na cidade de São Paulo. Saúde e Sociedade, 21(2), 351-363. Retirado de http://www.scielo.br/pdf/sausoc/v21n2/a09v21n2.pdf

Bardin, L. (1977/2011). Análise de Conteúdo (4ạ ed). São Paulo: Edições 70.

Boing, E., \& Crepaldi, M. A. (2010). O Psicólogo na Atenção Básica: uma incursão pelas políticas públicas de saúde brasileiras. Psicologia: ciência e profissão, 30(3), 634-649. doi: 10.1590/S1414-98932010000300014

Bittencourt, R. A. A., \& Mateus, M. L. F. (2006). Possibilidades de atuação do psicólogo no programa saúde da família: a experiência de Bonito-MS. Psicologia: Ciência e Profissão, 26(02), 328-343. doi: 10.1590/S1414-98932006000200014

Brasil. (1990). Estatuto da Criança e do Adolescente (ECA). BrasíliaDF. Retirado

http://www. planalto.gov.br/ccivil_03/LEIS/L8069.htm

Cardoso, C. L. (2002). A inserção do psicólogo no Programa Saúde da Família. Psicologia: ciência e profissão, 22(1), 2-9. doi: 10.1590/S1414-98932002000100002 
Cavalcante, C. M., Jorge, M. S. B., \& Santos, D. C. M. (2012). Onde está a criança? Desafios e obstáculos ao apoio matricial de crianças com problemas de saúde mental. Physis: Revista de Saúde Coletiva, 22(1), 161-178. doi:10.1590/S010373312012000100009

Cela, M., \& Oliveira, F. I. (2015). O psicólogo no Núcleo de Apoio à Saúde da Família: articulação de saberes e ações. Estudos de Psicologia, 20(1), 31-39. doi: 10.5935/1678-4669.20150005

Conti, F. D., \& Souza, A. S. L. (2010). O momento de Brincar no Ato de Contar Histórias: uma modalidade diagnóstica. Psicologia: Ciência e Profissão, 30(1), 98-113. doi:10.1590/S141498932010000100008

Conselho Federal de Psicologia. (2009). A Prática da Psicologia e o Núcleo de Apoio à Saúde da Família. Brasília - DF. Retirado de http: //site.cfp.org.br/wpcontent/uploads/2009/12/Seminxrio_O_Nxcleo_de_Apoiobeta.pdf

Dimenstein, M., \& Macedo, J. P. (2012). Formação em Psicologia: Requisitos para Atuação na Atenção Primária e Psicossocial. Psicologia: Ciência e Profissão. 32(n. esp.), 232-245. doi: 10.1590/S1414-98932012000500017

Finkel, L. A. (2009). O lugar da mãe na psicoterapia da criança - uma experiência de atendimento psicológico na saúde pública. Psicologia: Ciência e Profissão, 29(1), 190-203. doi: 10.1590/S1414-98932009000100016

Fontanella, B. J. B., Ricas, J., \& Turato, E. R. (2008). Amostragem por saturação em pesquisas qualitativas em saúde: contribuições teóricas. Cadernos de Saúde Pública, 24(1), 1727. doi: 10.1590/S0102-311X2008000100003

Fraser, M. T. D., \& Gondim, S. M. G. (2004). Da fala do outro ao texto negociado: discussões sobre a entrevista na pesquisa qualitativa. Paidéia, 14(28), 139-152. doi:10.1590/S0103$863 \times 2004000200004$

Jimenez, L. (2011). Psicologia na Atenção Básica à Saúde: demanda, território e integralidade. Psicologia \& Sociedade, 23(n. esp.), 129-139. doi: 10.1590/S0102-71822011000400016

Lima, M., Brito, M., \& Firmino, A. (2011). Formação em Psicologia no Contexto das Diretrizes Curriculares Nacionais: Uma Discussão sobre os Cenários da Prática em Saúde. Psicologia: Ciência e Profissão, 31(4), 856-867. doi:10.1590/S141498932012000400016

Mantovani, C. C. P., Marturano, E. M., \& Silvares, E. F. M. (2010). Abandono do atendimento em uma clínica-escola de psicologia infantil: variáveis associadas. Psicologia em Estudo, 15(3), 527535. Retirado http://www.scielo.br/pdf/pe/v15n3/v15n3a10.pdf 
Ministério da Saúde (2005). Caminhos para uma política de saúde mental infanto-juvenil. Brasília-DF. Retirado de http://bvsms.saude.gov.br/bvs/publicacoes/05_0887_M.pdf

Ministério da Saúde (2006). Política Nacional de Atenção Básica. Brasília-DF. Retirado de http://bvsms.saude.gov.br/bvs/publicacoes/politica_nacional_at encao_basica_2006.pdf

Richardson, R. J. (2011). Pesquisa social: métodos e técnicas. São Paulo: Atlas.

Silva, C. G. C., Serralha, C. A., \& Laranjo, A. C. S. (2013). Análise da Demanda e Implicação dos Pais no Tratamento Infantil. Psicologia em Estudo, 18(2), 281-291. Retirado de http://www.scielo.br/pdf/pe/v18n2/a09v18n2.pdf

Silva, R. M. M., \& Vieira, C. S. (2013). Acesso ao cuidado à saúde da criança em serviços de atenção primária. Revista Brasileira de Enfermagem, 67(5), 794-802. doi:10.1590/00347167.2014670518

Souza, R. A., \& Carvalho, A. M. (2003). Programa de Saúde da Família e qualidade de vida: um olhar da Psicologia. Estudos em psicologia, 8(3), 515-523. doi: 10.1590/S1413294X2003000300019

Sundfeld, A. C. (2010). Clínica ampliada na atenção básica e processos de subjetivação: relato de uma experiência. Physis: Revista de Saúde Coletiva, 20(4), 1079-1097. doi: 10.1590/S0103-73312010000400002

Zibetti, M. L. T., Souza, F. L. F., \& Queiróz, K. J. M. (2010). Quando a escola recorre à psicologia: mecanismos de produção, encaminhamento e atendimento à queixa na alfabetização. Estudos e Pesquisas em Psicologia UERJ, 10(2), 490-506. doi: 10.12957/epp.2010.8979

\section{Endereço para correspondência \\ Carolina Martins Pereira Alves}

Universidade Federal do Triângulo Mineiro - UFTM

Departamento de Psicologia

Av. Getúlio Guaritá, 159, sala 313, CEP 38025-440, Uberaba - MG, Brasil

Endereço eletrônico: carolmartins4@gmail.com

\section{Conceição Aparecida Serralha}

Universidade Federal do Triângulo Mineiro - UFTM

Departamento de Psicologia

Av. Getúlio Guaritá, 159, sala 313, CEP 38025-440, Uberaba - MG, Brasil

Endereço eletrônico: serralhac@gmail.com

Recebido em: 16/03/2016

Reformulado em: 28/10/2017

Aceito em: 18/10/2018 


\section{Notas}

* Graduação em Psicologia pela Universidade Federal do Triângulo Mineiro (UFTM), Especialização em Saúde da Criança e do Adolescente pela Residência Integrada Multiprofissional em Saúde da UFTM, Especialização em Saúde Mental pela Universidade Dom Bosco, Mestrado em Psicologia pela UFTM.

** Graduação em Psicologia pela Universidade Federal de Uberlândia (UFU), Mestrado e Doutorado pela Pontifícia Universidade Católica de São Paulo (PUC-SP). Professora Associada do Departamento de Psicologia e do Programa de PósGraduação em Psicologia da UFTM. Pós-doutorado em Psicologia pela Universidad Kennedy - Buenos Aires, Argentina, e em Filosofia da Psicanálise pela UNICAMP SP. Atuou como Professora Tutora da Residência Integrada Multiprofissional em Saúde da UFTM no período de 2010 a 2016.

Este artigo de revista Estudos e Pesquisas em Psicologia é licenciado sob uma Licença Creative Commons Atribuição-Não Comercial 3.0 Não Adaptada. 